\title{
Natural history of secundum atrial septal defect in adults after medical or surgical treatment: a historical prospective study
}

D Shah, M Azhar, C M Oakley, J G F Cleland, P Nihoyannopoulos

Department of

Cardiology)

Hammersmith

Hospital and the

Royal Postgraduate

Medical School,

London

D Shah

M Azhar

C M Oakley

J G F Cleland

P Nihoyannopoulos

Correspondence to:

Dr C M Oakley,

Department of Medicine

Department of Medicine
(Division of Cardiology),

(Division of Cardiology),

Hammersmith Hospital a
the Royal Postgraduate

the Royal Postgraduate

Road, London W12 ONN.

Accepted for publication

24 September 1993
Medicine (Division of

\begin{abstract}
Objective-To compare outcome in patients with medically treated secundum atrial septal defect (ASD) first diagnosed after the age of 25 with the long-term outcome in a similar group of patients after surgical closure.

Design-A historical, prospective, unrandomised study.

Setting-A tertiary referral centre.

Patients-All patients with ASD followed up since 1955 who fulfilled the entry criteria and had reached a current age of over 45 years-that is, 34 medical and 48 surgical patients with a mean follow up of 25 years.
\end{abstract}

Main outcome measures-Survival, symptoms, and complications.

Results-There was no difference in survival or symptoms between the two groups and no difference in the incidence of new arrhythmias, stroke or other embolic phenomena, or cardiac failure. No patient in either group developed progressive pulmonary vascular disease. Conclusion-Outcome in adults with ASD was not improved by surgical closure. Because progressive pulmonary vascular disease did not develop in any of these patients its prevention is not a reason for advising closure of ASD in adults.

(Br Heart ₹ 1994;71:224-228)

Atrial septal defect (ASD) was first described by Rokitansky in 1875 (cited by Edwards et al. ${ }^{1}$ Its clinical features were described in 1941 by Bedford et $a l^{2}$ and became well known with the writings of Barber et al, Wood and Leatham and Gray, ${ }^{3-5}$ in the 1950s. After bicuspid aortic valve it is the most common congenital defect in adults. Fuster et al reported an incidence of $22 \%$

Table 1 Clinical features of patients with complete follow up

\begin{tabular}{|c|c|c|c|c|}
\hline \multirow[b]{2}{*}{ Feature } & \multicolumn{2}{|c|}{ At presentation $(n=82)$} & \multicolumn{2}{|c|}{ At last follow up $(n=82)$} \\
\hline & Medical & Surgical & Medical & Surgical \\
\hline $\begin{array}{l}\text { No } \\
\text { Age (yr) (r } \\
\text { NYHA } \%\end{array}$ & $8 \cdot 6(25-54)$ & $\begin{array}{l}48 \\
36 \cdot 2 \cdot(26-51)\end{array}$ & $\begin{array}{l}34 \\
63(46-83)\end{array}$ & $\begin{array}{l}48 \\
62(48-81)\end{array}$ \\
\hline $\begin{array}{l}\text { I } \\
\text { II } \\
\text { Mean Qp/Qs shunts (range) } \\
\text { Mean PAP (range) } \\
\text { On diuretics (\%) }\end{array}$ & $\begin{array}{l}25(74) \\
9(26) \\
0 \\
2 \cdot 5(1 \cdot 8-4 \cdot 0) \\
34(22-42) \\
7(20)\end{array}$ & $\begin{array}{l}34(71) \\
14(29) \\
0 \\
2 \cdot 5(1 \cdot 6-3 \cdot 5) \\
30(20-44) \\
12(25)\end{array}$ & $\begin{array}{l}19(56) \\
15(44) \\
0(0) \\
= \\
\text { New } 8(24) \\
\text { Total } 15(44)\end{array}$ & $\begin{array}{l}26(54) \\
22(46) \\
0 \\
- \\
\bar{N} \text { ew } 13(27) \\
\text { Total } 25(52)\end{array}$ \\
\hline
\end{tabular}

PAP, pulmonary arterial pressure. among adults with congenital heart disease, ${ }^{6}$ but the true incidence is unknown as it is often not recognised until comparatively late in life or not at all. ${ }^{7}$ The defect is compatible with a normal life span $^{8}$-survival up to 94 years has been reported ${ }^{9}$-and ASD was well represented in a large necropsy series in the aged. ${ }^{10}$

Early studies of patients with ASD suggested high morbidity and reduced survival, ${ }^{11-14}$ but these patients were highly selected because at that time florid clinical signs of abnormality were needed before cardiac catheterisation was considered. The earliest open heart surgery was practised on such patients. ${ }^{15} 16$ Widespread modern medical screening and the availability of echocardiography has greatly increased detection of $\mathrm{ASD}^{1718}$ and made it even more important to know the natural history of this common defect.

The low mortality of surgical closure, even in older patients has been stressed. ${ }^{19}$ Patients have usually been advised to have their defects closed because their prognosis with an untreated defect was thought to be poor. ${ }^{12-1520}$ This approach meant that the long-term results of surgery were never compared with those of medical treatment.

We have compared the long-term outcome after surgical closure with the natural history of the uncorrected defect in a historical prospective study.

\section{Patients and methods}

All patients with uncomplicated ASD followed up at the Hammersmith Hospital since 1955 who were over 25 at presentation and had a current age of $>45$ years were entered into the study. We studied only patients with ostium secundum or sinus venosus defects (partial anomalous pulmonary venous drainage was not regarded as a complication), without severe pulmonary vascular disease (mean pulmonary artery systolic pressure $<45 \mathrm{~mm} \mathrm{Hg}$ ), without partial atrioventricular canal defects (ostium primum defects), and without any other cardiac abnormalities.

All the patients were seen again at the Hammersmith Hospital between October 1989 and March 1991.

Results

Table 1 shows the clinical and haemodynamic data of the 82 patients with complete follow up. There were 34 in the medical 
Table 2 Clinical features of patients lost to follow up

\begin{tabular}{lcl}
\hline At presentation & Medical & Surgical \\
\hline No & 7 & 15 \\
Age (yr) (range) & $30(25-36)$ & $37(27-51)$ \\
NYHA: & 5 & 12 \\
$\quad$ I & 2 & 5 \\
II & 0 & 0 \\
III & 0 & 0 \\
Atrial fibrillation & $2 \cdot 4(2 \cdot 0-3 \cdot 4)$ & $2 \cdot 6(2 \cdot 1-3 \cdot 2)$ \\
Mean Qp/Qs shunts & (range) & $30(22-38)$ \\
Mean PAP (range) & $24(20-34)$ & 1 \\
On diuretics & 0 & \\
\hline
\end{tabular}

PAP, pulmonary arterial pressure.

group and 48 in the surgical group. Their mean (range) ages when first seen or operated on were 39 (range 25-54) for the medical and $36(26-51)$ years for the surgical patients.

One hundred and five patients met the inclusion criteria. Follow up was complete in 82 patients $(78 \%)$. Of the 25 patients lost to follow up, six had emigrated and 12 had returned overseas. The remaining seven could not be traced but their names did not appear in the Home Office Register of Deaths. Their clinical and haemodynamic variables at presentation were similar to the rest of the patient population (table 2).

\section{CLINICAL FEATURES AT PRESENTATION}

More than $70 \%$ of patients in both groups were symptom free when first seen and had been identified at routine medical examinations but $10(29 \%)$ in the medical group and $17(35 \%)$ in the surgical group mentioned palpitation. Shortness of breath on exertion was described by nine (26\%) of the medical and $14(29 \%)$ of the surgical groups. Atrial fibrillation was most prevalent in older patients and was present in seven $(20 \%)$ in the medical and $12(25 \%)$ in the surgical group when they were first seen.

HAEMODYNAMIC VARIABLES AT PRESENTATION The mean (range) pulmonary artery pressure was $34(22-42) \mathrm{mm} \mathrm{Hg}$ in the medical group and $30(20-44) \mathrm{mm} \mathrm{Hg}$ in the surgical group (NS). The mean shunt flows were $2 \cdot 5: 1$ in each group and the ranges were comparable (medical $1 \cdot 8-4 \cdot 0: 1$, surgical $1 \cdot 6-3 \cdot 5: 1, \mathrm{NS}$ ).

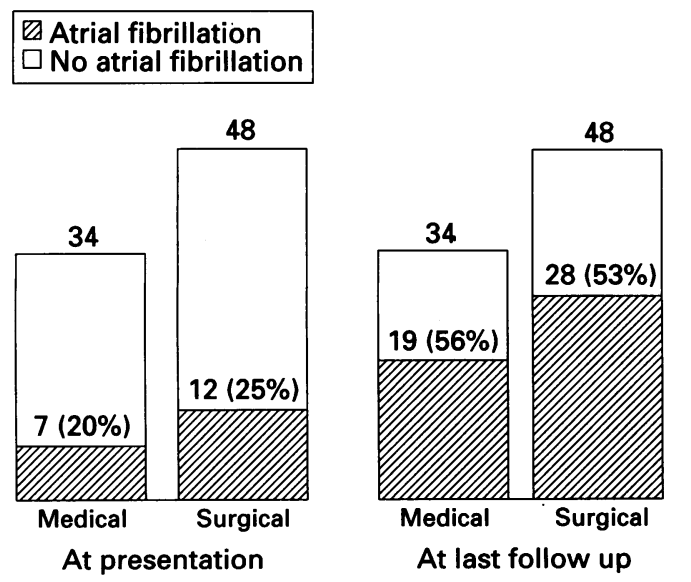

Distribution of atrial fibrillation
All patients had normal arterial oxygen saturations at rest but most showed small right to left shunts on indicator dilution curves.

\section{SURVIVAL AND DEATHS}

There were no operative or perioperative deaths. Early postoperative morbidity such as chest or wound infection is not considered in this comparison of the long-term health and wellbeing of operated and unoperated adults with ASD.

Eight patients died during follow up. Two patients in the surgical group and one in the medical group died from cardiovascular causes (fig 1). The duration of follow up (mean 25 years), the current mean ages (medical 63 years and surgical 62 years, NS), and the ranges for both groups were similar (NS). The oldest patient is in the medical group and is 83 years old.

\section{CLINICAL AND HAEMODYNAMIC VARIABLES AT}

THE LAST FOLLOW UP

More than $50 \%$ of all the patients were symptomatic at the last follow up. Fourteen (41\%) of the medical and $22(44 \%)$ of the surgical group complained of shortness of breath on effort; 19 (56\%) of the medical and 26 (54\%) of the surgical groups complained of palpitation, all of them were in chronic atrial fibrillation. The symptoms in the two groups showed no differences (NS).

In $12(35 \%)$ medical and $16(33 \%)$ surgical patients chronic atrial fibrillation developed during follow up. Nine (26\%) in the medical and $10(21 \%)$ in the surgical groups had episodes of supraventricular arrhythmia. Again there was no difference between the groups.

Fifteen (44\%) in the medical and 24 $(50 \%)$ in the surgical group were taking diuretics (NS) when last seen. The doses did not exceed $40 \mathrm{mg}$ frusemide or an equivalent in any patient.

\section{RE-EVALUATION}

\section{Haemodynamic studies}

Three patients in the medical group had repeat haemodynamic studies because of worsening symptoms - shortness of breath in two and fatigue in one. The new data were unchanged. All these patients continued medical follow up and are alive and well.

Four patients in the surgical group had repeat cardiac catheterisation, three for shortness of breath and one for fatigue. Only one patient showed incomplete closure of the defect. Repeat haemodynamic study in this patient showed a shunt size of $1 \cdot 3: 1$ with a mean pulmonary artery pressure of $26 \mathrm{~mm} \mathrm{Hg}$.

\section{ECHOCARDIOGRAPHY}

During the follow up period patients underwent a comprehensive cross sectional echocardiographic examination by Doppler, with a Toshiba SSH $65 \mathrm{~A}$ and SSH $160 \mathrm{~A}$ or General Electric Pass C cardiac ultrasound equipment. A 3,7 or $3.75 \mathrm{M} \mathrm{Hz}$ phased array transducer was used for optimal cross sectional imaging and 2 or $2.5 \mathrm{M} \mathrm{Hz}$ phased 
array transducers for Doppler calculations. Colour flow imaging was also used.

Of 30 patients in the non-surgical group, $13(43 \%)$ had tricuspid regurgitation that was mild in seven and moderate in six patients and thought to be secondary to a stretched tricuspid annulus. The average (SD) peak tricuspid regurgitant flow velocity was $3 \cdot 1(0.6) \mathrm{m} / \mathrm{s}$ and the average peak systolic gradient between the right atrium and ventricle was $39.04(14.3) \mathrm{mm} \mathrm{Hg}$. Conversely, of the 48 patients who had had had their ASD closed only eight $(17 \%)$ had mild functional tricuspid regurgitation $(p<0.05)$. The average peak tricuspid regurgitant flow velocity was $2 \cdot 7(0.6) \mathrm{m} / \mathrm{s}$ with an average peak systolic pressure gradient of $29 \cdot 5(13 \cdot 2) \mathrm{mm} \mathrm{Hg}$ (NS).

It was not possible to estimate right ventricular pressure in the other patients because they had no tricuspid regurgitation detected. Detected tricuspid reflux was more common in the medical group but there was no significant difference in the estimated right ventricular pressure and therefore no evidence of progressive pulmonary hypertension in the unoperated patients studied.

\section{Discussion}

This study included all our adult patients with asymptomatic or minimally symptomatic ASD at presentation. Because the reported complications of ASD tend to be higher after the fifth decade ${ }^{12-1421}$ we decided on a minimum age of 45 years at last follow up to increase the likelihood of detecting a difference between the groups. Clinical and haemodynamic characteristics at presentation in those not operated on were similar to those whose defects were closed surgically. The 25 patients lost to follow up had similar clinical and haemodynamic variables to the 82 patients reported here and there is no reason to think that outcome was different in these patients. Most had been referred from abroad.

Both our medical group and surgical group had similar long-term survival to that reported by Murphy et al for surgically treated patients ${ }^{20}$ but the $91 \%$ survival in our medical group is much better than in previously reported series of unoperated ASDs. ${ }^{12-14}$ This is not surprising because these early studies, when echocardiography was not available, selectively identified patients with obvious symptoms. We know now that symptoms are usually absent and clinical, electrocardiographic, and radiological signs are often unimpressive. Our ability to diagnose ASD improved considerably with experience of echocardiography and subsequent confirmation of a large shunt at catheterisation. Yet figures for natural history obtained from these early papers are still quoted. ${ }^{22}$ There are no other figures because routine closure of ASD has been practised since the early days of open heart surgery. Campbell et al suggested that $75 \%$ of patients are dead by the age of 50 years and $90 \%$ by $60,{ }^{11}$ but this was in 1957 when patients were only likely to have been referred because of symptoms, and therefore usually with heart failure and often with severe pulmonary hypertension. Many of the patients described in this paper would then have been regarded as having functional murmurs or mild pulmonary stenosis with a good prognosis and would not have been included in early series such as that of Campbell et $a l^{11}$ as they would not have been thought to warrant catheterisation. Though the longevity of our surgical group compares well with other reported series, ${ }^{19} 23$ our medical group shares the same longevity and shows no greater morbidity.

\section{ATRIAL FIBRILLATION}

Comparison of the incidence of development of atrial fibrillation, embolic episodes, and cardiac failure provided information on possible reduction of complications of ASD by surgical closure. At presentation seven (20\%) of the medical group and $12(25 \%)$ of the surgical group were in atrial fibrillation. At the last follow up 19 (56\%) of the medical group and $28(53 \%)$ of the surgical group were in atrial fibrillation. Thus $47(57 \%)$ out of 82 of all our patients were in atrial fibrillation and though their mean age at the last follow up was $>60$ years, this incidence is high compared with a control population. ${ }^{24}$ When the two groups were compared, however, the development of new atrial fibrillation in the medical and surgical patients was no different. Information on the prevalence of atrial fibrillation in unoperated patients with ASD is provided by preoperative data from operated series. ${ }^{2021}$ In our medical group the rate of atrial fibrillation was $45 \%$ in patients over the age of 40 , which is comparable with $51 \%$ in the series of Murphy et al for the same age group. ${ }^{20}$ In a population undergoing surgical closure in their sixties, St John Sutton et al reported a $58 \%$ preoperative rate of atrial fibrillation, which is comparable with $52 \%$ in our medical group of the same age. The rate of atrial fibrillation in our surgical group was $40 \%$ for patients in their 40 s and $58 \%$ for patients in their $60 \mathrm{~s}$. This compares well with published series after closure of ASD. ${ }^{19-23}$ Thus in our study the development of atrial fibrillation was neither reduced nor delayed by closure of ASD.

\section{SYSTEMIC EMBOLISM}

All the embolic episodes occurred in patients who had been in atrial fibrillation when last seen. The incidence of embolisation was similar in the two groups. The number of embolic complications in operated patients was similar to that in published series that also stressed the presence of atrial fibrillation. ${ }^{20-25}$ Though paradoxical embolism has been reported in patients with ASD (and also in those with only a patent foramen ovale), it is rare and was not recognised in our series. All patients with paroxysmal or established atrial fibrillation were treated with warfarin.

\section{CONGESTIVE FEATURES}

A high jugular venous pressure with tricuspid 
regurgitation may develop in patients with ASD who are in atrial fibrillation. ${ }^{1026}$ Forty five per cent of our medical and $50 \%$ of our surgical patients were receiving diuretics at the last follow up. All of them were in atrial fibrillation. The development of cardiac failure is reported to be multifactorial in patients with $\mathrm{ASD}^{2028-31}$ and it has been proposed that left ventricular dysfunction contributes to its development. ${ }^{29}{ }^{31}$ Left ventricular dysfunction was not detected by echocardiographic assessment performed in our patients at the last follow up. Though right ventricular dilatation was noted in both operated and unoperated patients, overall function remained good in both groups. Right ventricular thickness was within the normal range in both the medical and surgical groups at last follow up and cardiac failure in these patients was attributable to tricuspid regurgitation associated with atrial fibrillation as suggested by Wood. ${ }^{27} 28$ The frequency of raised venous pressure was not influenced by surgical treatment, though tricuspid regurgitation was detected more often by Doppler echocardiography in the unoperated group.

\section{PULMONARY VASCULAR DISEASE}

That we included patients both with dynamic pulmonary hypertension and moderate pulmonary vascular disease (resistance up to 11 Wood units) may be a cause for surprise; but we did not find clinical or Doppler echocardiographic evidence of progression of pulmonary vascular disease in any of our medical patients.

Patients with more severe pulmonary vascular disease had the pulmonary hypertension when they were first seen and were not included in this survey because all those with left to right shunts had their defects closed. Other patients with severe pulmonary vascular disease who had no significant shunts and small hearts at the time of presentation looked and behaved like patients with primary pulmonary hypertension with an ASD that was almost incidental.

In conclusion, with the increased detection rate of congenital heart disease in adults, which has resulted from more medical examinations and the availability of modern echocardiography, it has become even more important to know the likely natural history in order to offer the best treatment. Many benign abnormalities are now detected. Surgical intervention in people with few or no symptoms must be proved to be of benefit. Such benefit has never been shown in a randomised prospective series of adults with ASD and our experience suggests that delayed closure of ASD in adult life does not alter the natural history. Neither survival nor the incidence or timing of development of atrial arrhythmias, embolic stroke, pulmonary vascular disease, or heart failure were affected by surgery in our patients whose defects had not been detected until adulthood. The main problems were the development of atrial fibrillation and embolic stroke. These should be preventable by anticoagulant treatment. Both medically and surgically treated patients had similar morbidity though this was higher than in the normal population. We suggest that routine surgical closure of ASD in adults is not justified because it does not influence future morbidity, which remains higher than in the normal population. Atrial septal defects should of course be detected and closed during childhood when it is believed (but has not been shown) that subsequent differential growth and remodelling improves the longterm outlook for retention of sinus rhythm.

1 Edwards JE, Carey LS, Neufeld HN, et al. Congenital heart disease: correlation of pathologic anatomy and angiography. Vol 1. Philadelphia: WB Saunders, 1965:191-234.

2 Bedford DE, Papp C, Parkinson J. Atrial septal defect. Br Heart f 1941;3:37-68.

3 Barber JM, Magidson D, Wood P. Atrial septal defect. Br Heart f 1950;12:277-9.

4 Wood P. Congenital heart disease (St Cyres Lectures). $B M F$ 1950;11:639 and 693.

5 Leatham A, Gray I. Auscultatory and phonocardiographic signs of atrial septal defect. Br Heart $\mathcal{F} 1956 ; 18: 193-6$.

6 Fuster V, Brendenburg RO, McGoon DC, et al: Clinical approach and management of congenital heart disease in the adolescent and adults. Cardivasc Clin 1980;10: 161-97.

7 Seldon WA, Rubstein C, Fraser AA. The incidence of atrial septal defect in adults. $B r$ Heart $\mathcal{F} 1962 ; 24$ : 552-62.

8 Colmers RA. Atrial septum defect in elderly patients: report of three patients aged 68,72 , and 78 years. $A m \mathcal{F}$ Cardiol 1958;1:768-73.

9 Perloff JK. Ostium secundum atrial defect-survival for 87 and 94 years. Am $\mathcal{F}$ Cardiol 1984;53:388-9.

10 Rodstein M, Zeman FD, Gerber IE. Atrial septal defect in the aged. Circulation 1961;23:665-74.

11 Campbell M, Neil C, Suzman S. The prognosis of atrial septal defect. Br Heart $\mathcal{f} 1957 ; 1: 375-83$

12 Markman P, Howitt G, Wade EG. Atrial septal defect in the middle aged and elderly. $Q \mathcal{F}$ Med 1965;34:409-26.

13 Craig RJ, Selzer A. Natural history and prognosis of atrial septal defect. Circulation 1968;37:805-15.

14 Campbell M. Natural history of atrial septal defect. Br Heart f 1970;32:820-6.

15 Blount SG, Swan H, Gensini G, McCord MC. Atrial septal defect. Clinical and physiologic response to closure in five patients. Circulation 1954;9:801.

16 Cleland WP, Bentall HH, Oakley CM, Goodwin JF. A decade of cardiac surgery. Lancet 1967;1:191-8.

17 Radtke WE, Tajik AJ, Gau GT, et al. Atrial septal defect: echocardiographic observations; studies in 120 patients. Ann Intern Med 1976;84:246-53.

18 Weyman AE, Wann LS, Caldwell RL, et al. Negative contrast echocardiography: a new method for detecting left trast echocardiography: a new method for dete
to right shunts. Circulation 1979;59:140-50.

19 Saksena FB, Aldridge HE. Atrial septal defect in the older patients: a clinical and hemodynamic study in patients operated on after age 35. Circulation 1970;42:1009-20.

20 Murphy GJ, Gersh BJ, McGoon MD, et al. Long-term outcome after surgical repair of isolated atrial septal defect: follow-up at 27 to 32 years. $N$ Engl $₹$ Med 1990; 323:1644-50.

21 St John Sutton MG, Tajik AJ, McGoon MD, et al. Atrial septal defect in patients aged 60 years or older: operaseptal defect in patients aged 60 years or older: opera-
tive results and long-term follow-up. Circulation 1981; 64:402-9.

22 Horvath KA, Burke RP, Collins JT, Cohn LH. Surgical treatment of adult atrial septal defect: early and longterm results. F Am Coll Cardiol 1992;20:1156-9.

23 Decoff GR, Brandenburg RO, et al. Results of operation for atrial septal defect in patients forty-five years and older. Circulation 1967;35(suppl I):I-143-7.

24 Kannel WB, Aboot RD, Savage DD, McNamara AF. Epidemiologic features of chronic atrial fibrillation. N Engl f Med 1982;306:1018-20.

25 Hawe A, Rastelli GC, Brandenburg RO. Embolic complication following repair of atrial septal defects. Circulation cation following repair of a
1969;39(suppl 1):185-91.

26 Dexter L. Atrial septal defect. Br Heart $\mathcal{F}$ 1956;18:209-25.

27 Wood P. Diseases of the heart and circulation. 3rd ed. London: Eyre and Spottiswoode.

28 Wood P. Fate of the child with unrelieved congenital heart disease. Atrial septal defect. In: Morse DP ed. Congenital heart diseases: an international symposium. Oxford: Blackwell Scientific Publications, 1962:49.

29 Bonow RO, Borer JS, et al. Left ventricular functional reserve in adults with atrial septal defect: pre- and postoperative studies. Circulation 1981;63:1315-22.

30 Levin AR, Leibston PR, Ehler KH, Diamant B. Assessment of left ventricular function in secundum atrial septal defect: evaluation by determination of volume, pressu

31 Booth DC, Weisenbaugh $T$, Smith $M$. Left ventricular distensibility and passive elastic stiffness in atrial septal defect. F Am Coll Cardiol 1988;12:1231-6. 


\section{Comment}

The decision whether or not to close an atrial septal defect in adults is a difficult one. The paper from Hammersmith that appears on pages 224 to 228 is based on Celia Oakley's conservative approach over the past 25 years and provides a breath of fresh air.

In people with an atrial septal defect pulmonary vascular resistance is actually reduced (possibly because of pulsatile flow). High pulmonary vascular resistance rarely or only coincidentally develops. It is useful to see this confirmed. Over the years many cardiologists will have wondered whether a rise of venous pressure with the onset of atrial fibrillation in elderly people with an atrial septal defect indicates that they should have been referred for surgery earlier. It is reassuring to read that atrial fibrillation and heart failure were as common in the operated group as in the non-operated group. The question that remains is whether or not there is a haemodynamic benefit from closure of the atrial septal defect. Many of us have probably recommended that closure is advisable in physically active people but not worthwhile in those who are sedentary and it is unfortunate that cardiac output on exertion was not compared in the operated and non-operated groups in the Hammersmith paper. A hint in favour of the concept of recommending closure for physically active patients is that tricuspid regurgitation (presumably judged by a dominant systolic wave in the neck) was found in $43 \%$ of the non-operated group but in only $17 \%$ of the operated group. Another argument in favour of surgery is eradication of the threat of paradoxical embolism.

AUBREY LEATHAM 